\title{
Molecular mechanisms of genome expression of coxsackievirus B3 that belongs to enteroviruses
}

\author{
Mariola Dutkiewicz *, Agata Swiatkowska, Agata OJdowska, Barbara Smólska, \\ Teresa DyMarek-Babś, AnNa Jasińska, Jerzy CiesioŁKa \\ Institute of Bioorganic Chemistry, Polish Academy of Science, Poznań, Poland \\ *Corresponding author: mariolad@ibch.poznan.pl
}

\begin{abstract}
Coxsackievirus B3 (CVB-3) belongs to the Picornaviridae family of enterovirus genus of pathogens that cause a great number of human diseases. A viral infection is associated with many pathological states such as: myocarditis, dilated cardiomyopathy, pericarditis, pleurodynia, systemic infection in infants, aseptic meningitis, and pancreatitis. Since viral diseases, especially in their chronic state, are difficult to treat, there has not been as yet, any specific therapeutic developed against coxsackievirus till date. CVB-3 is a single stranded, positive-sense RNA virus that encodes one large open reading frame flanked by two untranslated regions (UTR). The $5^{\prime} \mathrm{UTR}$ contains an IRES element that directs the translation process and a cloverleaf structure that regulate viral replication. The complementary, $3^{\prime}$ terminal region of the replicative strand is also believed to be crucial for the replication of events. The secondary structure RNA elements regulate the most important processes in the viral propagation cycle. The mechanisms that rule the CBV-3 gene expression, its genome structure and the key steps of its viral life cycle are being reviewed in the hope that better knowledge of these processes will lead to better understanding of the molecular biology of CVB-3 and to the design of an effective therapy against this enterovirus.
\end{abstract}

Key words: enterovirus, coxsackievirus B3, untranslated region, IRES-dependent translation, cloverleaf structure, viral replication

\section{Inroduction}

Enteroviruses are the largest group of the Picornaviridaefamily and significant human pathogens. The most intensely investigated enterovirus is poliovirus (PV) which causes a disease named polio (poliomyelitis). Many years of global polio eradication and a widespread attempt to control the number of poliovirus infections have also triggered an interest in other enteroviruses such as coxsackievirus B3 (CVB-3).

Because both, CVB as well as PV, viruses show some similarities in the structure and life cycle, coxsackieviruses are often used to serve as a safer working model to understand the molecular mechanism of PV pathology, whereas the study of polioviruses helps to expand the knowledge of CVB-3 biology.

The term coxsackievirus has been derived from a small town - Coxsackie - in New York, USA where the virus was isolated for first time by Dalldorf and Sickles in 1948 (Dalldorf and Sickles, 1948). It was observed that an isolated virus could protect against the polio effect. This work provided the first evidence of the exi- stence of uncharacterised human enteroviruses. At present, there are more than one hundred human and simian enteroviruses that are known to exist, of which 23 are classified as coxsackievirus A, although only 6 serotypes belong to the coxsackievirus B group (Hyypiä et al., 1997).

The CVB infection is associated with the wide spectrum of diseases. It can cause inflammation of the membranes that cover the brain and the spinal cord (meningitis), the heart muscle (myocarditis) and the pericardium (pericarditis). It has been estimated that approximately $30 \%$ of all recently diagnosed myocarditis have resulted from CVB infection (Horwitz et al., 2006). The complications of viral myocarditis may develop dilated cardiomyopathy. In case of an infant virus infection, a systemic inflammation frequently occurs and leads to a cardiac arrest and death in 50\% of the cases (Tracy and Gauntt, 2008). The coxsackievirus infection may also increase the risk of a chronic fatigue syndrome (CFS). The persistent infection of the human pancreatic islet cells that resembles the loss of beta-cell function in auto- 
immune diabetes seems to be one of the significant diseases caused by coxsackieviruses. It is thought that pancreas inflammation (pancreatitis) is, in many cases, the result of the coxsackievirus $B$ infection.

\section{Virus genome structure and organization}

Coxsackievirus B3 is around $30 \mathrm{~nm}$ in diameter and lacks the lipid-protein membrane (Muckelbauer et al., 1995). The genetic material of the virus is enclosed in the icosahedral capsid which is made up of 12 pentamer elements. Each pentamer is composed of four viral structural proteins: VP1, VP2, VP3 and VP4. There is a region of narrow depression termed canyon around each of the pentamer axes, and it is a specific site of interaction with cell receptors.

Alike all Picornaviridae, CVB-3 genome is a singlestranded positive sense RNA containing two untranslated regions, $5^{\prime} \mathrm{UTR}$ and $3^{\prime} \mathrm{UTR}$, which flank a single open reading frame (ORF). The length of the entire CVB-3 genome is approximately $7400 \mathrm{nt}$, with ca. $6500 \mathrm{nt}$ of ORF (Lindberg et al., 1987; Racinello, 2007). The $5^{\prime}$ end of the viral RNA contains the structural elements that are essential for virus propagation cycle (Liu et al., 2009).

The coding part of the coxsackieviral genome is divided into three blocks: P1, P2 and P3. The structural proteins are encoded by $\mathrm{P} 1$ whereas the non-structural proteins are expressed from P2 and P3 parts of the virus genome. The $5^{\prime}$ end of viral RNA is covalently linked to VPg protein and poly $(\mathrm{A})$ tail is present at the $3^{\prime}$ end (Lindberg et al., 1987; Racinello, 2007).

It is believed that coxsackieviruses are closely related to polioviruses. The genome organization is very similar in both viruses and their non-structural proteins play the same role in their replication. Insertion of the $5^{\prime}$ UTR of coxsackievirus B3 into a poliovirus genome resulted in obtaining a chimera virus with a phenotype similar to the wild-type which was capable of reproducing in a cell culture (Semler et al., 1986; Johnson and Semler, 1988). On this basis, in the present review, description of the molecular biology of CVB-3 has been supported in many cases by the research on poliovirus.

\section{Propagation cycle}

The virus life cycle lasts approximately from 5 to 10 hours depending on the serotype. CVB-3 mostly recruits CAR receptor (coxsackie- and adenovirus receptor) to initiate the infection. Other serotypes coxsackievirus B and many other enteroviruses can also attach to CD55 receptor (known as DAF - decay accelerating factor) (Racinello, 2007; Sean and Semler, 2008).

The conformational changes in the nucleocapsid which results from low $\mathrm{pH}$ or from interactions with some co-receptors (integrin $\alpha \mathrm{V} \beta 6$ ), facilitate the release of viral genetic material into the host cell. In contrast to DNA viruses, positive-strand RNA viruses do not pass to the nucleus and viral RNA can be immediately used as an mRNA template for the translation of viral proteins (Fig. 1).

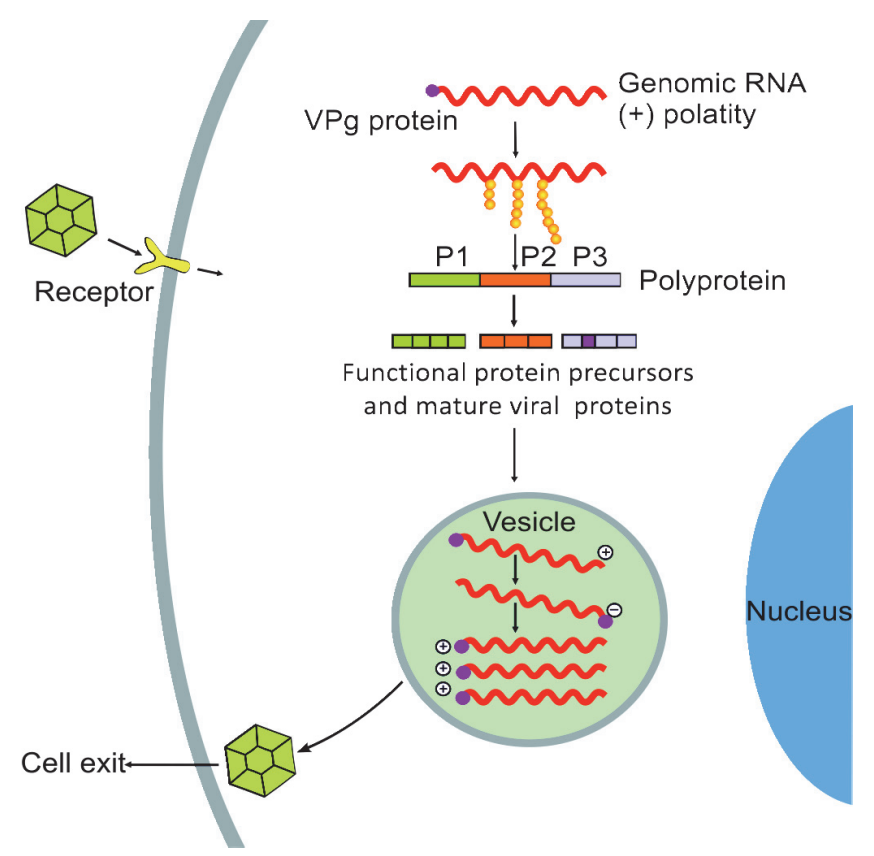

Fig. 1. Schematic representation of the life cycle of enteroviruses

A single ORF is translated into viral polyprotein, it is then processed to functional proteins which are not only a mature but also a precursor form. Viral RNA encodes RNA-dependent RNA polymerase (RdRp), capsid proteins, proteases and several other proteins. Soon after the translation of viral proteins, the production of cellular proteins is halted, mainly because of the activation of viral proteases $2 \mathrm{~A}$ and $3 \mathrm{C}$, which cleave the crucial capdependent translation factors.

During replication, viral RNA is used as a template to synthesize the complementary negative-strand RNA. Replication events occur in cytoplasm where the replication complex is attached to membranes derived from the endoplasmic reticulum and Golgi complex. Not only viral proteins and host factors are necessary to produce 


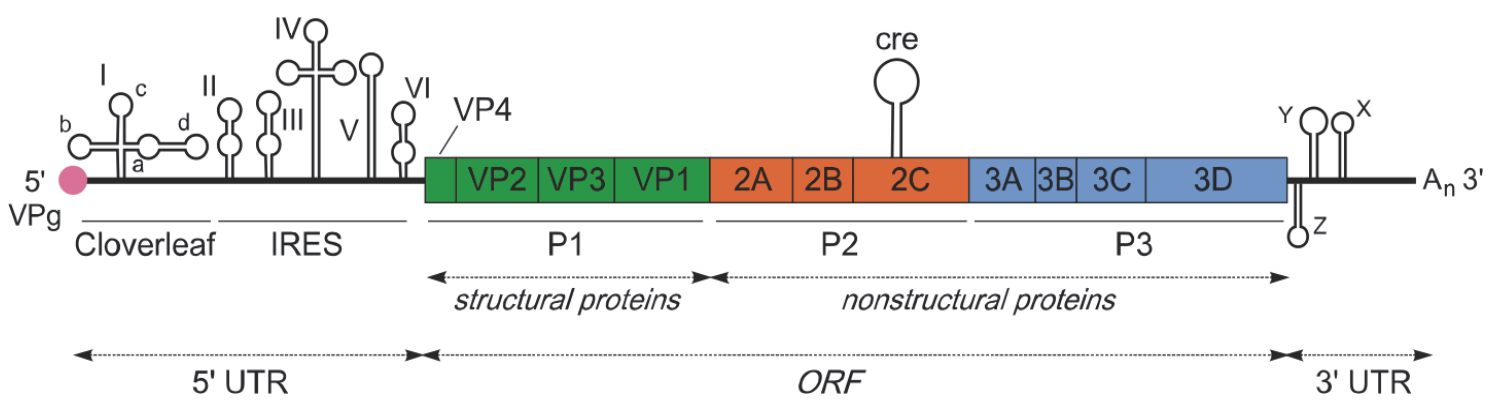

Fig. 2. Genome organization of CVB-3

negative-strand RNA but the uridylylated VPg (VPgpUpU) is required as well. It subsequently acts as a primer to allow the initiation of a positive-stand RNA replication. The newly synthesized RNAs can be used as templates in the next round of translation but most of them are packaged into virions and are released by cell lysis. It is also believed that mature virions can leave host cell via the secretory pathway (Sean and Semler, 2008; Wong et al., 2008).

\section{Viral proteins}

Translation from a single ORF leads to a large polyprotein, ca. $250 \mathrm{kDa}$, of approximately 2200 amino acids which is composed of structural proteins ( $\mathrm{P} 1 \mathrm{block}$ ) and non-structural proteins (P2 and P3 blocks) - Figure 2. The polyprotein undergoes multi-steps proteolytic processing mediated by its two major proteinases: $2 \mathrm{~A}$ and $3 \mathrm{C}$. The $\mathrm{P} 1 / \mathrm{P} 2$ junction is cleaved by proteinase $2 \mathrm{~A}$ then the $\mathrm{P} 2 / \mathrm{P} 3$ junction is processed by proteinase $3 \mathrm{C}$ to generate mature viral proteins.

Since the virus genome is small and encodes only few proteins of which most are multifunctional, the precursors also take part in the regulation of virus life cycle. The characteristics of viral functional proteins are presented in Table 1. The majority of information on viral proteins comes from research conducted on poliovirus and to a large extent are in consensus with those on coxsackievirus (Oberste et al., 2008; Sean and Semler, 2008).

\section{IRES-dependent translation}

It took a long time to explain how viral proteins can be produced when a cap-dependent translation is strongly impaired by the eIF $4 \mathrm{G}$ inactivation (one of essential canonical initiation translation factors) via viral protease cleavage. It was even more surprising when it turned out that VPg protein which was believed to be cap analog, is removed before virus entry into the host cell. The answer was brought by the discovery of Internal Ribosome Entry Site (IRES) which is a highly structured RNA element present in the $5^{\prime}$ UTR of genomic RNA. This element has been found in all enteroviruses and many other viruses, but was first shown for poliovirus (Pelletier and Sonenberg, 1988).

Gene expression of coxsackievirus is mostly controlled at the translation level. Viral RNA after entry into host cell is directly used as a template for the production of viral proteins. In contrast to most cellular mRNAs that are templates for a cap-mediated translation, viral RNAs recruit ribosome via the IRES structural elements.

After translation, $2 \mathrm{~A}$ and $3 \mathrm{C}$ viral proteases process not only viral polyprotein but cleave cellular proteins as well to shutoff host gene expression on both transcription and translation levels. Cellular translation is inhibited 2 hours after infection; however, 5 hours post-infection viral translation is also impaired (Bonderoff and Lloyd, 2008).

\section{IRES structure and function}

Both the structure and sequence of the $5^{\prime} \mathrm{UTR}$ is highly conserved among all enteroviruses (Bailey and Tapprich, 2007; Oberste, 2008). The stable secondary structure organization of IRES makes the recruitment of ribosome possible without the involvement of the cap element. Type I IRES binds 40S small ribosomal subunits in the presence of canonical translation factors and non-canonical factors - IRES trans-acting factors (ITAF) then RNA is scanned to find the translation initiation codon. Cellular proteins seem to be chaperons that maintain a proper secondary structure of IRES and facilitate its contact with the translational machinery in order to modulate the efficiency of protein synthesis (Sean and 
Table 1. Enteroviral proteins (data were compiled based on: Racinello, 2007; Sean and Semler, 2008; Lin et al., 2009)

\begin{tabular}{|c|c|c|}
\hline Protein & Features and functions & Consequences of expression in cell and activity \\
\hline $\begin{array}{l}\text { VP1, } \\
\text { VP2, } \\
\text { VP3, } \\
\text { VP4 }\end{array}$ & $\begin{array}{l}\text { - VP1 and VP3 interact with each other while VP4 stabilizes this interaction } \\
\text { VP1, VP2, and VP3 have no sequence homology, but the same topology since they form an eight-stranded } \\
\text { antiparallel b-barrel } \\
\text { - extended conformation of VP4 } \\
\text { - the C-termini are placed on the surface of the virion whereas the N-termini are located inside }\end{array}$ & $\begin{array}{l}\text { - VP1, VP2, VP3, and VP4 form a basic structure of the } \\
\text { icosahedral capsid }\end{array}$ \\
\hline $2 \mathrm{~A}$ & $\begin{array}{l}\text { - cysteine proteinase structure similar to chymotrypsin } \\
\text { - viral polyprotein processing at the P1/P2 junction } \\
\text { - cleavage of host translational factors, i.e. eIF4G, PABP } \\
\text { - cleavage of TBP (TATA - binding protein) in vitro, but without host transcription inhibition } \\
\text { - cleavage of cytoceratin } 8 \text {, dystrophin protein (which may be the factor leading to cardiomyopathy)(CVB-3) }\end{array}$ & $\begin{array}{l}\text { - impairment of host cap-dependent translation } \\
\text { - can induce cell apoptosis } \\
\text { - suggested to be a factor that blocks nucleo-cyto- } \\
\text { plasmic traffic }\end{array}$ \\
\hline $2 \mathrm{BC}$ & $\begin{array}{l}\text { - the precursor of viral proteins: } 2 \mathrm{~B} \text { and } 2 \mathrm{C} \\
\text { - the accumulation of } 2 \mathrm{BC} \text { or } 2 \mathrm{~B} \text { proteins on Golgi changes the permeability of plasma membrane, disrupts } \\
\text { Golgi complex and leads to cell lysis }\end{array}$ & $\begin{array}{l}\text { - negative impact on the secretion pathway } \\
\text { - an increase in the level of free } \mathrm{Ca} 2+\text { in cells } \\
\text { - membranous alteration in the infected cells }\end{array}$ \\
\hline $2 \mathrm{~B}$ & $\begin{array}{l}\text { - the N-terminus can form a cationic, amphipathic } \alpha \text {-helix, characteristic to ionophores } \\
\text { - interaction with membranous vesicles }\end{array}$ & $\begin{array}{l}\text { - a decrease in the level of free } \mathrm{Ca} 2+\text { in } \mathrm{ER} \text { and Golgi } \\
\text { - caspase pathway inhibition } \\
\text { - membranous alteration in the infected cells }\end{array}$ \\
\hline $2 \mathrm{C}$ & $\begin{array}{l}\text { - the presence of two Cys-rich, zinc-binding domain } \\
\text { - RNA-binding domains at both N- and C-termini } \\
\text { - membrane-binding element at the N-terminus } \\
\text { - a helicase motif but no helicase activity proved } \\
\text { - ATPase activity } \\
\text { - interaction with membranous vesicles } \\
\text { - direct interaction with the } 3 \text { 'end of replicative strand }\end{array}$ & $\begin{array}{l}\text { - induction of membranous vesicles formation } \\
\text { - possibly anchoring the }(-) \text { strand in membrane of } \\
\text { - suggested importance during }(-) \text { strand synthesis due } \\
\text { to ATP hydrolysis }\end{array}$ \\
\hline
\end{tabular}


Continued Table 1

\begin{tabular}{|c|c|c|}
\hline Protein & Features and functions & Consequences of expression in cell and activity \\
\hline $3 \mathrm{AB}$ & $\begin{array}{l}\text { - the precursor of viral proteins: } 3 \mathrm{~A} \text { and } 3 \mathrm{~B} \\
\text { - hydrophobic domain at the N-part (3A part) } \\
\text { - interaction with membranous vesicles, 3D(RdRp) and } 3 \mathrm{CD} \\
\text { - forms alternative RNP-complex on cloverleaf(+) with } 3 \mathrm{CD} \\
\text { - can be a direct substrate in VPg uridylylation }\end{array}$ & $\begin{array}{l}\text { - anchoring replicative complex in membrane of virus- } \\
\text { induced vesicles } \\
\text { - stimulates autoproteolysis of } 3 \mathrm{CD} \text { and activity of } \\
\text { RdRp } \\
\text { - suggested RNA chaperone function due to helix } \\
\text { destabilization }\end{array}$ \\
\hline $3 \mathrm{~A}$ & $\begin{array}{l}\text { - less conserved picornaviral protein, a membrane-binding protein } \\
\text { - possible functional homodimerization } \\
\text { - hydrophobic domain harbour } \\
\text { - interaction with membranous vesicles }\end{array}$ & $\begin{array}{l}\text { - disruption of ER-to-Golgi traffic } \\
\text { - inhibition of cellular secretion and transport }\end{array}$ \\
\hline $\begin{array}{l}3 \mathrm{~B} \\
(\mathrm{VPg})\end{array}$ & $\begin{array}{l}\text { - a peptide covalently attached to the } 5^{\prime} \text { end of all picornaviral genomes } \\
\text { - interaction with } 3 \mathrm{D} \\
\text { - undergoes uridylylation by } 3 \mathrm{Dpol} \text { at the third position of tyrosine }\end{array}$ & $\begin{array}{l}\text { - uridylylated form (VPg-pUpU) serves as a primer } \\
\text { during both stages of replication: synthesis of }(+) \text { and } \\
(-) \text { strands } \\
\text { - protection the } 5^{\prime} \text { end of genomic RNA from cellular } \\
\text { exonucleases }\end{array}$ \\
\hline $3 \mathrm{CD}$ & $\begin{array}{l}\text { - the precursor of viral proteins: } 3 \mathrm{C} \text { and } 3 \mathrm{D} \\
\text { - functional proteinase cleaves glutamine - glycine bonds } \\
\text { - possible interaction with other } 3 \mathrm{CD} \text { molecules, } 3 \mathrm{C} \text { or } 3 \mathrm{D} \\
\text { - interacts with PCBP and domain I in the } 5^{\prime} \mathrm{UTR} \text { forming a ternary complex } \\
\text { - able to enter into nuclei } \\
\text { - interacts with the } 3^{\prime} \mathrm{UTR} \text {, the cre element, } 3 \mathrm{AB} \text { as well as with host proteins: PABP and hnRNP C }\end{array}$ & $\begin{array}{l}\text { - a component of functional RNP complexes serving in: } \\
\text { VPg uridylylation on the cre element, initiation of }(-) \\
\text { strand synthesis and initiation of }(+) \text { strand synthesis } \\
\text { - viral protein processing } \\
\text { - mediates viral genome circularization }\end{array}$ \\
\hline $3 \mathrm{C}$ & $\begin{array}{l}\text { - cysteine proteinase, similar in structure to serine protease - chymotrypsin } \\
\text { - viral polyprotein processing of the P2 and P3 blocks } \\
\text { - interaction with domain I in the } 5^{\prime} \mathrm{UTR} \\
\text { - cleavage of host translational and transcriptional factors, i.e. - eIF4G, eIF4AI, PABP, TBP, p53, OCT-1, CREB } \\
\text { also microtubulin-associated protein } 4\end{array}$ & $\begin{array}{l}\text { - inhibition of host cap-dependent translation and } \\
\text { transcription } \\
\text { - induction of cell apoptosis }\end{array}$ \\
\hline 3D Pol & $\begin{array}{l}\text { - RNA dependent RNA polymerase (RdRp) } \\
\text { - right-hand conformation } \\
\text { - responsible for the VPg uridylylation } \\
\text { - cooperatively binds to at least } 10 \mathrm{nt} \text { stretch of RNA } \\
\text { - RNA unwinding activity } \\
\text { - interaction with } 3 \mathrm{AB} \text { and host protein Sam } 68 \\
\text { - able to oligomerize }\end{array}$ & $\begin{array}{l}\text { - a clue enzyme in replication due to uridylylation of } \\
\text { VPg and RNA elongation } \\
\text { - similar to helicase activity requiring for RNA synthe- } \\
\text { sis to disrupt the secondary structures and unwind } \\
\text { RNA(+)/RNA(-) heteroduplex }\end{array}$ \\
\hline
\end{tabular}


Semler, 2008; Fernández-Miragall et al., 2009; Bonderoff and Lloyd, 2008; Belsham et al., 2009).

CVB and poliovirus IRES is approximately $490 \mathrm{nt}$ in length and is located within the $5^{\prime}$ UTR which is approximately $750 \mathrm{nt}$. Internal ribosome entry site contains domains: II, IV, V and VI of the $5^{\prime}$ UTR (Fig. 2). Both CVB3 and PV characterize type I IRES in which AUG codon is located approximately $100 \mathrm{nt}$ downstream of $3^{\prime}$ end of the IRES.

The pyrimidine-rich region linking domain $\mathrm{V}$ and $\mathrm{VI}$ precedes AUG codon. It was believed that Py-xx-AUG region was a counterpart of Shine-Dalgarno sequence (Shine-Dalgarno-like motif, SD-like). However, as it turns out, this AUG codon is not used as a translation initiation codon but is the next downstream AUG that serves as translation start site.

The most characteristic motifs of IRES are: GNRA tetra-loop which is responsible for a long range RNA-RNA interaction, $\mathrm{A} / \mathrm{C}$ rich loops in domain $\mathrm{IV}$ and $\mathrm{V}$ which stimulate IRES activity, and GAGA loop in domain VI.

It is interesting to note that despite of similarity between coxsackie- and poliovirus, much shorter IRES can tolerate larger deletions and be still functional in case of CVB-3, whereas PV requires mostly the entire structure of IRES for translation (Bonderoff and Lloyd, 2008).

\section{Shutoff of cellular proteins translation}

It was believed that eIF4G cleavage was sufficient to shut off host translation. However, it has been shown that it only strongly impairs the production of cellular proteins (Bonderoff and Lloyd, 2008). Most detailed studies have revealed that two fragments of eIF4G are generated by viral protease $2 \mathrm{~A}$. The $\mathrm{C}$-terminal part is used in viral translation while the $\mathrm{N}$-terminal end binds eIF4E and PABP and it is also able to circularize the viral genome, although the $40 \mathrm{~S}$ ribosome subunit recruitment is lost.

A two-step mechanism has been proposed to explain how the host translation is switched off. The first stage is eIF4G cleavage and the second one is based on the $\mathrm{PABP}$ inactivation. PABP is a substrate for both $2 \mathrm{~A}$ and $3 \mathrm{C}$ viral proteases. During PV and CVB-3 RNA replication, PABP is cleaved. Since the $3 \mathrm{C}$ preferentially attacks polysome-associated PABP, there is still a high concentration of free PABP in cells that can be used to circularize viral RNA. PABP cleavage results in a 10-ti- mes weaker host translation due to the lack of the viral genome circularization. However, cellular protein production cannot be ceased completely only by the PABP inactivation (Bonderoff and Lloyd, 2008, FernándezMiragall et al., 2009, Filbin and Kieft, 2009).

\section{Protein involving in assembly of translation initiation complex}

It is still not clear as to which eukaryotic translation initiation factors (eIFs) are crucial for translation. A set of eIFs specific for each virus group seems to be required.

Canonical translation factors are used in cap-dependent processes, particularly at the initiation stage. In the case of IRES-mediated translation eIF2, eIF3, eIF4A and eIF $4 \mathrm{~F}$ or $1 / 3$ eIF $4 \mathrm{G}$ (binding to IRES by HEAT domain) are indispensable (Filbin and Kieft, 2009). Moreover, non-canonical factors: PTB, PCBP2 (poly $(\mathrm{rC})$ binding protein 2), $\mathrm{La}$ (Lupus autoantigen) and unr are required for poliovirus and La, PTB, PCBP2 are required for CVB3 translation as well (Walter et al., 1999; Ray and Das, 2002; Cheung et al., 2007; Sean et al., 2009; Verma et al., 2010).

It is believed that eIF4G, PABP (eIF4B/La) are needed for RNA circularization. La proteins may not stimulate translation alone but together with other ITAFs they may facilitate the assembly of a translation initiation complex. There are many La binding sites in each IRES element, especially GAGA motif in domain VI (Bonderoff and Lloyd, 2008). The active conformation of IRES is supported by polypyrimidine tract-binding protein (PTB). Moreover, in vitro and in vivo translation is stimulated by PTB. Another non-canonical factor which plays a role in the translation and replication process is poly $(\mathrm{rC})$ binding protein (PCBP). It is assumed that PCBP may stabilize the active form of IRES by interacting with the domain IV loop. Binding of PCBP to its second site in IRES (the cloverleaf element) seems to be important for the translation-replication transition; however, PCBP dimerization is required (Bonderoff and Lloyd, 2008).

\section{Viral replication}

The replication mechanism is similar among enteroviruses and it begins 2.5 hours post infection. Specific secondary structures of viral RNA, viral proteins in mature and precursor form and some cellular factors are necessary to efficiently replicate viral genetic material. 
Proteins allow the formation of the membrane-bound replication complex and coordinate all interactions occurring during RNA synthesis.

Similar to other positive-sense RNA viruses, two-step replication is also a characteristic of coxsackievirus. During the first step, a negative-strand RNA is synthesized and then a positive-strand RNA is produced using the negative-strand RNA as a template. Both replication steps take place in membranous vesicles probably formed by disintegration of the endoplasmic reticulum membranes and the viral proteins-induced disintegration of the Golgi complex. It is believed that the role of the membranous vesicles is positioning of the replication complex to facilitate RNA synthesis. Moreover, they may maintain proper concentrations of all the components necessary for replication and protect newly-synthesized RNAs from nucleases (Wong et al., 2008).

The formation of membranous vesicles is induced by $2 \mathrm{~B}, 2 \mathrm{C}, 2 \mathrm{BC}$ and $3 \mathrm{~A}$ viral proteins. Mature forms of these proteins probably act as an anchor for the replication complex. $3 \mathrm{AB}$ and $3 \mathrm{CD}$ precursors provide a template for the replication machinery whereas $2 \mathrm{C}$ protein anchors the entire replication complex into a vesicle membrane (Sean and Semler, 2008). Direct interaction of $2 \mathrm{C}$ protein to negative-strand RNAs was shown for PV and can be important for their movement inside the membranous vesicles during the second step of replication (Banerjee et al., 1997, 2001; Sean and Semler, 2008).

\section{Structural elements of RNA involved in viral replication}

It has been estimated that more than $10 \%$ of the enterovirus genome is non-coding. Regions that flank ORF contain structural elements which are important for the virus life cycle. The $5^{\prime} \mathrm{UTR}$ is about $750 \mathrm{nt}$ in length whereas the $3^{\prime} \mathrm{UTR}$ is composed of $70 \mathrm{nt}$ for poliovirus and $120 \mathrm{nt}$ for coxsackievirus. The $3^{\prime}$ terminal end of viral genome is poly (A) tail varying in length.

Highly structured elements of enterovirus RNA interact with both viral and host proteins (Sean and Semler, 2008; Lin et al., 2009; Li and Nagy, 2011). The most significant elements are: cloverleaf $\left(5^{\prime} \mathrm{CL}\right)$, which plays a key role in viral replication and protects the viral genome from cellular endonucleases, as well as IRES that is responsible for translation initiation.

The cruciform-like secondary structure (also named stem-loop I, cloverleaf - the $5^{\prime} \mathrm{CL}$ or domain I) is pre- sent at the $5^{\prime}$ end of viral genome (Fig. 2). Mutagenesis studies on PV and CVB-3 have demonstrated that the presence of the $5^{\prime} \mathrm{CL}$ is crucial for the synthesis of both negative and positive-strand RNAs and VPg uridylylation (Sharma et al., 2009; Vogt and Andino, 2010; Ogram and Flanegan, 2011). The cloverleaf structure is composed of four stem-loop elements (SL a-d). C-rich track in an apical loop of SL $d$ is required for the interaction with cellular protein - PCBP whereas SL b loop binds viral $3 \mathrm{CD}$ protein. The tertiary complex is formed in CVB-3, $\mathrm{PV}$ and other enteroviruses by interactions of PCBP, $3 \mathrm{CD}$ and domain $\mathrm{I}$ is required for replication (Andino et al., 1990; Bell et al., 1999). Moreover, its presence prevents coping of cellular mRNA containing poly (A) tail and protects the terminal sequence of viral RNA against its loss (Sean and Semler 2008).

A stable secondary structure is also proposed at the $3^{\prime}$ end of viral replicative strand. It is believed that it may reflect the cloverleaf element and it seems to be the initiation site of a positive-strand RNA synthesis. In vivo work on PV revealed that hnRNP $\mathrm{C}$ (heterogenous ribonucleoprotein $\mathrm{C}$ ) and viral $2 \mathrm{C} / 2 \mathrm{BC}$ proteins interact with this structure (Banerjee, 2001; Brunner, 2005; Ertel, 2010).

A highly structured element resembling tRNA (tRNA-like, L-shaped conformation) which can be folded as a pseudoknot is located at the $3^{\prime}$ end of viral RNA. Stem-loops $\mathrm{X}$ and $\mathrm{Y}$ are predicted in the $3^{\prime} \mathrm{UTR}$ of poliovirus whereas three stem-loops $\mathrm{X}, \mathrm{Y}$ and $\mathrm{Z}$ are probably formed at the $3^{\prime}$ end of coxsackievirus genome. Deletion mutations have shown that domain $Z$ is not essential in the replication process. In both cases, $\mathrm{PV}$ and coxsackievirus tertiary interactions described above resulted from interactions between stem-loop X and Y. A disruption of this interaction results in a delay of RNA synthesis for PV while for CVB it is lethal. It is assumed that a pseudoknot is important for the initiation of a negative-strand RNA synthesis (van Ooij et al., 2006a, 2006b; Zoll et al., 2009).

The poly(A) tail at the terminal end of viral 3'UTR resulted from the presence of poly $(\mathrm{U})$ in the replicative strand. This means that it is genetically encoded in contrast to the poly(A) track of a cellular mRNA which is added by poly(A) polymerase. The length of a viral poly(A) is approximately $60-80 \mathrm{nt}$. Its interaction with cellular PABP may facilitate viral genome circularization that is required for a negative-strand RNA synthesis. PABP-independent replication of a negative-strand RNA has been 
also suggested and in this case poly(A) tail might play a role in increasing the efficiency of VPg uridylylation and initiation of the negative-strand RNA synthesis (Sean and Semler, 2008; Fernández-Miragall et al., 2009).

Within the region encoding $2 \mathrm{C}$ protein, a stem-loop structure named cisacting replication element - cre is present. It takes part in the replication process as well. This element serves as a template for uridylylation of VPg or VPg-containing precursors. Within a 14-nucleotide loop of coxsackieviral cre hairpin the conserved AAAUG sequence is present, while in PV it is AAACA sequence. In both cases, the first two adenosine residues are indispensable for covalent link UMP nucleotides to VPg via viral polymerase (van Ooij et al., 2006c). A decrease in the efficacy of positive-strand RNA synthesis was observed for $\mathrm{PV}$ when the cre sequence or structure was disrupted. In the case of CVB-3, the cre element is engaged in both steps of replication (van Ooij et al., 2006c; Shean and Semler, 2008).

VPg uridylylation seems to be also supported by the cloverleaf structure. The $5^{\prime} \mathrm{CL}$ is not directly involved in VPg uridylylation but it may act as a scaffold for proteins which are important for this process (Ogram and Flanegan, 2011).

\section{Translation - replication switch}

Prior to the replication initiation, viral RNA must be released from ribosomes to avoid a potential disruption of both translation and replication complexes and pretermination of RNA synthesis. In the replication process, all proteins encoded by the $\mathrm{P} 2$ and P3 blocks are required. It is believed that an accumulation of non-structural proteins triggers the transition from translation to replication.

Transition appears to be initiated by the interaction of $3 \mathrm{CD}$ protein with domain I in $5^{\prime} \mathrm{UTR}$ which then increases the PCBP2 affinity for the same structural element. This results in a decreased pool of free PCBP2 that could take part in the translation. Since potential $3 \mathrm{C} / 3 \mathrm{CD}$ cleavage sites within $\mathrm{PCBP} 2$ were revealed, it is probable that viral protease can cleave PCBP2 to release a fragment of this protein. A truncated form of PCBP2 cannot be used in the translation but it is still functional in the replication process because of its ability to interact with domain I. Both the transposition and the cleavage of PCBP cause the loss of its ITAF features and in consequence the
IRES-dependent translation is strongly impaired (Sean and Semler, 2008; Bonderoff and Lloyd, 2008).

\section{Replication complex assembly and negative-strand RNA synthesis}

The crucial element for replication is the tertiary complex at the $5^{\prime}$ end of viral RNA. It is required for a template circularization presumably via interaction with PABP-poly(A) complex to place the replication complex near the $3^{\prime}$ end of RNA.

The adenosine residues present in poly(A) tail are used as a template for VPg uridylylation by 3D viral polymerase $\left(3 \mathrm{D}^{\mathrm{pol}}\right)$. Uridylylated VPg (VPgpUpU) attaches to the $3^{\prime}$ end of poly (A) and it acts as a starter for polymerase. Then the replication complex with the $3 \mathrm{D}^{\mathrm{pol}}$ elongates a new negative-strand RNA. The synthesis is completed when the complex reaches the $5^{\prime}$ end of viral RNA genome.

Heteroduplex RNA (named as the replicative form $-\mathrm{RF}$ ) that is formed by the newly synthesized and the template RNAs is predicted for all Picornaviridae. It is assumed that RF is unfolded until the second step of replication occurs but the mechanism is unknown yet. The replicative strand is shorter than genomic RNA because of the internal starter annealing. The synthesis of a positive-strand RNA with proper length poly(A) track may partially result from the "slipping" of polymerase on poly $(\mathrm{U})$ tail present in the replicative strand (Sean and Semler, 2008).

\section{Positive-strand RNA synthesis}

The second step of replication requires domain I $\left(5^{\prime} \mathrm{CL}\right)$ present at the $5^{\prime}$ end of genomic strand, the cre element and a short primary RNA element, 10nt in length from the 3 ' end of replicative strand, as shown for PV (Sharma, 2005; Sean and Semler, 2008; Ogram and Flanegan, 2011). The $3 \mathrm{CD}, 3 \mathrm{D}^{\mathrm{pol}}$ and $2 \mathrm{C}$ viral proteins and host hnRNP $\mathrm{C}$ are involved in the initiation of positive-strand RNA synthesis (Banerjee et al., 2001; Brunner et al., 2005; Lin et al., 2009; Ertel et al., 2010).

VPg uridylylation is effectively performed using the cre as a template to generate excess of uridylylated VPg. Then, the tertiary complex and VPgpUpU are delivered close to the $3^{\prime}$ end of negative-strand RNA.

Prior to starter annealing and initiation of replication, the $3^{\prime}$ end must be released from heteroduplex RF. 
Secondary structures stabilized by proteins, formed at the $5^{\prime}$ end of the positive-strand of RF and also probably at the $3^{\prime}$ end of the replicative strand, facilitate strand separation. Then hnRNP C binds near the $3^{\prime}$ end of negative-strand RNA that helps to expose terminal andenosine residues complementary to the starter (Brunner et al., 2005). After replication complex formation, the $3 \mathrm{D}^{\mathrm{pol}}$ elongates new positive-strand RNA.

As a result of positive-strand RNA synthesis, a replicative intermediate (RI) which partially exhibits doublestranded features is formed. The presence of secondary structures of nascent RNA prevents total annealing of both RNA strands as otherwise pre-termination of the replication process might occur. Another mechanism based on helicase activity of RdRp (3D ${ }^{\mathrm{pol}, \mathrm{c}}$ capable of unfolding a fragment of $1000 \mathrm{nt}$ ) was also proposed. Additionally, the $3 \mathrm{AB}$ might play a similar role due to its helix-destabilizing activity. Multiple positive-strand RNAs can be generated simultaneously on one template. It has been suggested that all necessary components may be accumulated in the $3 \mathrm{D}^{\mathrm{pol}}$ lattice (Sean and Semler, 2008; Steil and Barton, 2009).

It has been estimated that the ratio of positive-strand RNA to negative-strand RNA is approximately 40:1. One of the proposed explanations is the inefficient VPg uridylylation based on poly (A) template in comparison with cre dependent uridylylation which takes place during the positive-strand RNA synthesis. Such discrepancy between negative- and positive-strand RNA pools seems to reflect different functions of both strands. The negative-strand RNA serves only as a template to generate new RNA whereas positive-strand RNA is involved in many events of virus life cycle such as translation, replication, and virion assembly. Moreover, the synthesis of replicative strand occurs shortly after viral infection when viral proteins are less available while positive-strand RNA production is not limited in this way (Sean and Semler, 2008).

\section{Concluding remarks}

This article reviews the available information on CBV-3 genome structure, the mechanisms of its gene expression, and key steps of viral life cycle. Despite a large progress in studies on CBV-3 in recent years there are still some viral processes and structures not fully characterized. In some cases, knowledge on poliovirus has been helpful in understanding the coxsackie- viral biology. However, there are still areas on the molecular map of CVB-3 and PV which have not yet been elucidated or which are represented merely by suggestions and theoretical models. Only a few significant differences between these two viruses have been demonstrated at the molecular level and therefore intensive efforts should be continued, in particular to research CBV-3, to help design an effective and specific therapy against this enterovirus.

\section{Acknowledgments}

This work was supported by the Polish Ministry of Science and Higher Education (grant no. N N302 385537 to M. D.).

\section{References}

Andino R., Rieckhof G.E., Baltimore D. (1990) A functional ribonucleoprotein complex forms around the $5^{\prime}$ end of poliovirus RNA. Cell 63: 369-380.

Bailey J.M., Tapprich W.E. (2007) Structure of the $5^{\prime}$ Nontranslated Region of the Coxsackievirus B3 Genome: Chemical Modification and Comparative Sequence Analysis. J. Virol. 81: 650-668.

Banerjee R., Echeverri A., Dasgupta A. (1997) PoliovirusEncoded 2C Polypeptide Specifically Binds to the 3'-Terminal Sequences of Viral Negative-Strand RNA. J. Virol. 71: 9570-9578.

Banerjee R., Tsai W., Kim W., Dasgupta A. (2001) Interaction of Poliovirus-Encoded 2C / 2BC Polypeptides with the $3^{\prime}$ Terminus Negative-Strand Cloverleaf Requires an Intact Stem-Loop b. Virology 280: 41-51.

Bell Y.C., Semler B.L., Ehrenfeld E. (1999) Requirements for $R N A$ replication of a poliovirus replicon by coxsackievirus B3 RNA polymerase. J. Virol. 73: 9413-9421.

Belsham J.G. (2009) Divergent picornavirus IRES elements. Virus Res. 139: 183-192.

Bonderoff J.M., Lloyd R.E. (2008) CVB Translation: Lessons from the Polioviruses. Curr. Top. Microbiol. Immunol. 323: 123-147.

Brunner J.E., Nguyen J.H.C., Roehl H.H., Ho T.V., Swiderek K.M., Semler B.L. (2005) Functional interaction of heterogeneous nuclear ribonucleoprotein $C$ with poliovirus RNA synthesis initiation complexes. J. Virol. 79: 32543266 .

Cheung P., Lim T., Yuan J., Zhang M., Chau D., McManus B., Yang D. (2007) Specific interaction of HeLa cell proteins with coxsackievirus B3 3'UTR: La autoantigen binds the $3^{\prime}$ and $5^{\prime} U T R$ independently of the poly $(A)$ tail. Cell. Microbiol. 9: 1705-1715.

Dalldorf G., Sickles G.M. (1948) An Unidentified, Filtrable Agent Isolated From the Feces of Children With Paralysis. Science 108: 61-62.

Ertel K.J., Brunner J.E., Semler B.L. (2010) Mechanistic Consequences of hnRNP C Binding to Both RNA Termini of 
Poliovirus Negative-Strand RNA Intermediates. J. Virol. 84: 4229-4242.

Fernández-Miragall O., López de Quinto S., Martínez-Salas E. (2009) Relevance of RNA structure for the activity of picornavirus IRES elements. Virus Res. 139: 172-82.

Filbin M.E., Kieft J.S. (2009) Toward a structural understanding of IRES RNA function. Cur. Opp. Struct. Biol. 19: 267-276.

Horwitz M.S, Knudson M., Ilic A., Fine C., Sarvetnick N. (2006) Transforming growth factor-betainhibits coxsackievirus-mediated autoimmune myocarditis. Viral Immunol. 19: $722-733$

Hyypiä T., Hovi T., Knowles N.J., Stanway G. (1997) Classification of enteroviruses based on molecular and biological properties. J. Gen. Virol. 78: 1-11.

Johnson V.H., Semler B.L. (1988) Defined recombinants of poliovirus and coxsackievirus: sequence-specific deletions and functional substitutions in the $5^{\prime}$-noncoding regions of viral RNAs. Virology 162: 47-57.

Li Z., Nagy P.D. (2011) Diverse roles of host RNA-binding proteins in RNA virus replication. RNA Biol. 8: 305-315.

Lin J., Chen T., Weng K., Chang S., Chen L., Shih S. (2009) Viral and host proteins involved in picornavirus life cycle. J. Biomed. Sci. 14: 1-14.

Lindberg A.M., Stalhandske P.O., Pettersson U. (1987) Genome of coxsackievirus B3. Virology 156: 50-63.

Liu Y., Wimmer E., Paul A.V. (2009) Cis-acting RNA elements in human and animal plus-strand RNA viruses. Biochim. Biophys. Acta 1789: 495-517.

Muckelbar J.K., Kremer M., Minor I., Diana G., Dutko F.J., Groarke J., Pevear D.C., Rossmann M.G. (1995) The Structure of Coxsackievirus B3 at 3.5A Resolution. Curr. Biol. 3: 653-667

Oberste M.S. (2008) Comparative Genomics of the Coxsackie $B$ Viruses and Related Enteroviruses. Curr. Top. Microbiol. Immunol. 323: 33-48.

Ogram S.A., Flanegan J.B. (2011) Non-Templated Functions of Viral RNA in Picornavirus Replication. Curr. Opin. Virol. 1: 339-346.

Ooij M.J., Glaudemans D.H., Heus H.A., Kuppeveld F.J., Melchers W.J. (2006a) Structural and functional integrity of the coxsackievirus B3 oriR: spacing between coaxial RNA helices. J. Gen. Virol. 87: 689-695.

Ooij M.J., Polacek C., Glaudemans D.H., Kuijpers J., Kuppeveld F.J., Andino R., Agol V.I., Melchers W.J. (2006b) Polyadenylation of genomic $R N A$ and initiation of antigenomic RNA in a positive-strand RNA virus are controlled by the same cis-element. Nucl. Acids Res. 34: 29532965.

Ooij M.J., Vogt D.A., Paul A., Castro C., Kuijpers J., Kuppeveld F.J., Cameron C.E., Wimmer E., Andino R., Melchers W.J. (2006c) Structural and functional characterization of the coxsackievirus B3 CRE (2C): role of CRE (2C) in negative-and positive-strand RNA synthesis. J. Gen. Virol. 87: 103-113.
Pelletier J., Sonenberg N. (1988) Internal initiation of translation of eukaryotic $m R N A$ directed by a sequence derived from poliovirus RNA. Nature 334: 320-325.

Racaniello V.R. (2007) Picornaviridae: The Virus and Their Replication. in: Field's Virology, ed. Fields B.N., Knipe D.M., Howley P.M., Griffin D.E., Martin M.A., Lippincott Williams \& Wilkins a Wolter Kulwer business, p. 795-838.

Ray P.S., Das S. (2002) La autoantigen is required for the internal ribosome entry site-mediated translation of Coxsackievirus B3 RNA. Nucl. Acids Res. 30: 4500-4508.

Sean P., Nguyen J.H., Semler B.L. (2009) Altered interactions between stem-loop $I V$ within the 5 noncoding region of coxsackievirus $R N A$ and poly $(r C)$ binding protein 2: Effects on IRES-mediated translation and viral infectivity. Virology 389: 45-58.

Sean P., Semler B.L. (2008) Coxsackievirus B RNA Replication: Lessons from Poliovirus, Curr. Top. Microbiol. Immunol. 323: 89-121.

Semler B.L., Johnson V.H., Tracy S. (1986) A chimeric plasmid from cDNA clones of poliovirus and oxsackievirus produces a recombinant virus that is temperature-sensitive. Proc. Natl. Acad. Sci. USA. 83: 1777-1781.

Sharma N., Donnell B.J., Flanegan J.B. (2005) 3-Terminal Sequence in Poliovirus Negative-Strand Templates Is the Primary cis-Acting Element Required for VPgpUpUPrimed Positive-Strand Initiation. J. Virol. 79: 3565-3577.

Sharma N., Ogram S.A., Morasco B.J., Spear A., Chapman N.M., Flanegan J.B. (2009) Functional role of the $5^{\prime}$ terminal cloverleaf in Coxsackivirus $R N A$ replication. Virology 393: 238-249.

Steil B.P., Barton D.J. (2009) Cis-active RNA elements (CREs) and picornavirus $R N A$ replication. Virus Res. 139: 240-252.

Tracy S., Gauntt C. (2008) Group B Coxsackievirus Virulence. Curr. Top. Microbiol. Immunol. 323: 49-66.

Verma B., Bhattacharyya S., Das S. (2010) Polypyrimidine tract-binding protein interacts with coxsackievirus B3 RNA and influences its translation. J. Gen. Virol. 91: 12451255.

Vogt D.A., Andino R. (2010) An RNA Element at the 5'-End of the Poliovirus Genome Functions as a General Promoter for RNA Synthesis. PLoS Pathogens. 6:e1000936.

Walter B.L., Nguyen J.H., Ehrenfeld E., Semler B.L. (1999) Differential utilization of poly $(r C)$ binding protein 2 in translation directed by picornavirus IRES elements. RNA 5: 1570-1585.

Wong J., Zhang J., Si X., Gao G., Mao I., McManus B.M., Luo H.L. (2008) Autophagosome Supports Coxsackievirus B3 Replication in Host Cells. J. Virol. 82: 9143-9153.

Zoll J., Heus H.A., Kuppeveld F.J., Melchers W.J. (2009) The structure - function relationship of the enterovirus 3-UTR. Virus Res. 139: 209-216. 